\title{
Seasonal Dynamics of Tropical Forest Vegetation in Ngoc Linh Nature Reserve, Vietnam Based on UAV Data
}

\author{
Nguyen Dang Hoi ${ }^{1}$, Ngo Trung Dung ${ }^{1 *}$ \\ 1 Institute of Tropical Ecology, Vietnam-Russian Tropical Centre, № 63, Nguyen Van Huyen Str., Cau Giay \\ District, Hanoi, Vietnam. \\ * Correspondence author: ngotrungdung266@gmail.com; Tel.: +84-936-332-201
}

\begin{abstract}
Seasonal dynamics in tropical forests are closely related to the variation in forest canopy gaps. The canopy gaps change continuously in shape and size between the rainy and dry seasons, leading to the variation in the vegetative indicators. To monitor the variation of the canopy gaps, UAVs were used to collect datas in the mentioned tropical forests at an altitude of over 1,000m in Ngoc Linh Nature Reserve, Vietnam with a post-processing image resolution of about $8 \mathrm{~cm}$, which allows the detection of relatively small gaps. The analysis results at 10 squares of 1 ha showed a decrease in the area of canopy gaps from the rainy season in September 2019 to the dry season of May 2020. The mixed broad-leaved or broadleaf forest dominates with a greater variation, when the area of the gaps decreases significantly. The variation in forest canopy gaps and vegetative indicators are closely related to the high differentiation of terrain, the seasonal and the dry season climatic characteristics. The fluctuation of the vegetation cover affects the habitats of the species under the forest canopy such as animals, birds and soil fauna. This is one of the scientific bases that contributes to the management and conservation of flora and fauna biodiversity, especially in mountainous tropical forests such as Ngoc Linh Nature Reserve.
\end{abstract}

Keywords: Canopy gaps; drone; Seasonal variation; Triangular Greenness Index (TGI); Tropical forest

\section{Introduction}

Tropical forests are considered to be the highest-biodiversity ecosystems on earth. In Vietnam, tropical forests occupy a large area, with a high diversity of vegetation cover and forest species composition. The deep differentiation of topography, climate and human impacts creates the diversity and abundance of forest vegetation types: closed evergreen broadleaf forest, mixed broadleaf and coniferous forests, forests coniferous forests, lowland broad leaved tropical forests, deciduous forests (Trung, 1978).

In the process of formation and development, the factors representing the forest status have important implications in forest research. One of those states is the "void" of the forest canopy. The term "canopy gap" was accepted early by Watt (Watt, 1947). Later, the concept of canopy gaps was introduced in many studies, such as from the 80 's by Collins (Collins et al., 1985), Hubbell (Hubbell \& Foster, 1986), and van der Maarel (van der Maarel, 1988). Accordingly, most authors acknowledge that the canopy gap is an important indicator in evaluating the structure and stages of each forest type (Eysenrode et al., 2002; Forman \& Collinge, 1997; Richards et al., 1996; Whitmore, 1989). The forest canopy gaps allow sunlight to penetrate easily, creating a living space and energizing the regenerating vegetation under the canopy. The forest canopy gap plays an important role in the forest ecology, with impacts on the nutrient cycle of the forest vegetation cover, a factor in promoting the forest succession process. Previous studies have shown that they directly affect the intensity of light, soil moisture and soil biological properties, which are factors that directly affect the growth and development of trees (Gagnon et al., 2003; Muscolo et al., 2014).

The canopy gaps have varied shapes and disturbances, with many different sizes and shapes. The impacts of each type of canopy gap on the environment also differ markedly according to shape and size. How bright and warm the gaps are, is due to increased radiation and the uptake of more 
water-filled soil surfaces by reduced evaporation of plants (Denslow, 1987). Since then, the properties of soil microorganisms, physical and chemical properties and metabolic cycle in the soil also change. Therefore, the sizes and shapes of a gap is a necessary indicator in assessing the structure and variation in cycles, especially seasonal variation in tropical forests. In addition, disturbance and unevenness in the canopy gaps are different conditions for forest regeneration. The term "void dynamics" has been coined to clarify this issue (Brokaw \& Busing, 2000; Kimmins, 2004; van der Maarel, 1988). Therefore, we can pose numerous solutions in conserving and regenerating natural forests. The size of the canopy gaps strongly affects the growth of vegetation, vegetative cycles of plants and a number of different biological processes in the soil (Gray et al., 2002; Muscolo et al., 2007).

The age considerations of the canopy gaps have also been extensively studied. Forest vegetation is always developing and changing over time, reflected in the differences between seasons or stages and cycles of forests. Studies on regenerated tree density and canopy gap were of interest by Bongjoh and Mama (Bongjoh \& Mama, 2020). Reflecting differences in light conditions under the stratum and forest structure. In old-growth tree areas, where there is little space, sapling formation and regeneration take place much more slowly (Hart \& Grissino-Mayer, 2009). It is said that in regenerating forests, where there are large gaps, there is the driving force to change the composition of plant species (Caron et al., 2009; Kirchner et al., 2011). They offered recommendations for the scaling of canopy gaps which increase forest heterogeneity, motivating the development of mature forests (Betts et al., 2005). Meanwhile, the degree of regeneration of the natural forest was used to compare measurements between the canopy cover and the canopy cover of forests in Northeast Italy (Marchi \& Paletto, 2010).

Currently, there are many methods for measuring and mapping forest canopy gaps. According to Getzin et al. (2014), the most effective tool for spatial measurement and mapping of forest canopy gaps is remote sensing (Getzin et al., 2014). However, in order to cover a large area of tropical forests, remote sensing images with a resolution of more than $2 \mathrm{~m}$ are not suitable due to low accuracy and error (Bullock et al., 2018; Csillik et al., 2020; Elhag, 2015). The over-reliance on satellite-mounted remote sensing devices or UAV has resulted in inconsistent results for small-scale ecological research (Anderson \& Gaston, 2013). LiDAR technologies have also been applied in many aspects (Chung \& Huang, 2020). Including research on forest canopy structure and support for forest management (Fernandez-Diaz et al., 2020; Nieschulze et al., 2012; Wulder et al., 2008). However, the expensive price is a big problem for researchers.

UAVs are currently used quite commonly in the field of forestry and forest management. Its advantages are its high resolution, flexibility in data collection at different times and relatively low cost (Banu et al., 2016; Brovkina et al., 2018). Being proactive and flexible in-flight time, highly accurate data, rarely affected by clouds, is an important criterion in mapping forest management (Anderson \& Gaston, 2013; Banu et al., 2016). These highlights help UAVs gradually become an effective means of supporting ecologists, making measurements suitable for the scale of each different ecological process (Getzin et al., 2014).

In our study, the Phantom 4 Advanced UAV was used in the field of coniferous mixed forest in Ngoc Linh Nature Reserve, Vietnam to compare and assess seasonal variation of rain forest (rainy season September 2019 and the dry season May 2020) through two vegetative indicators: Canopy gaps, Triangular Greenness Index (TGI). The variation in the TGI in the canopy gaps between the dry season and the rainy season is an important criterion for evaluating the development of tropical forests. The flight capture area will be divided into 10 plots with an area of 1 ha each. The main purpose is to assess the correlation between the TGI index, and the canopy gaps formed between the wet and dry seasons in the mixed broadleaf and coniferous forests. The research results will be related and explained to the phenomena and laws of growth and development of the tropical forest ecosystem at an altitude of over $1,000 \mathrm{~m}$ in the tropics. Seasonal dynamic analysis of tropical forest vegetation is the basis for developing management and conservation plans for forest species, especially those living under the forest canopy, having a growth and development cycle based on seasonal dynamics of the forest vegetation. 


\section{Materials and Methods}

\subsection{Study site}

Ngoc Linh Nature Reserve (Ngoc Linh NR) in Kon Tum province was established in 2002, with a natural area of 41,429 ha. Ngoc Linh NR is located in a mountainous area of the southernmost mountainous region of the Central region, connected to the mountain circuit of Quang Nam - Quang Ngai - Binh Dinh of Truong Son Nam, with the summit of Ngoc Linh 2,598m high. In 2019, Ngoc Linh NR recognized ASEAN Heritage Garden.

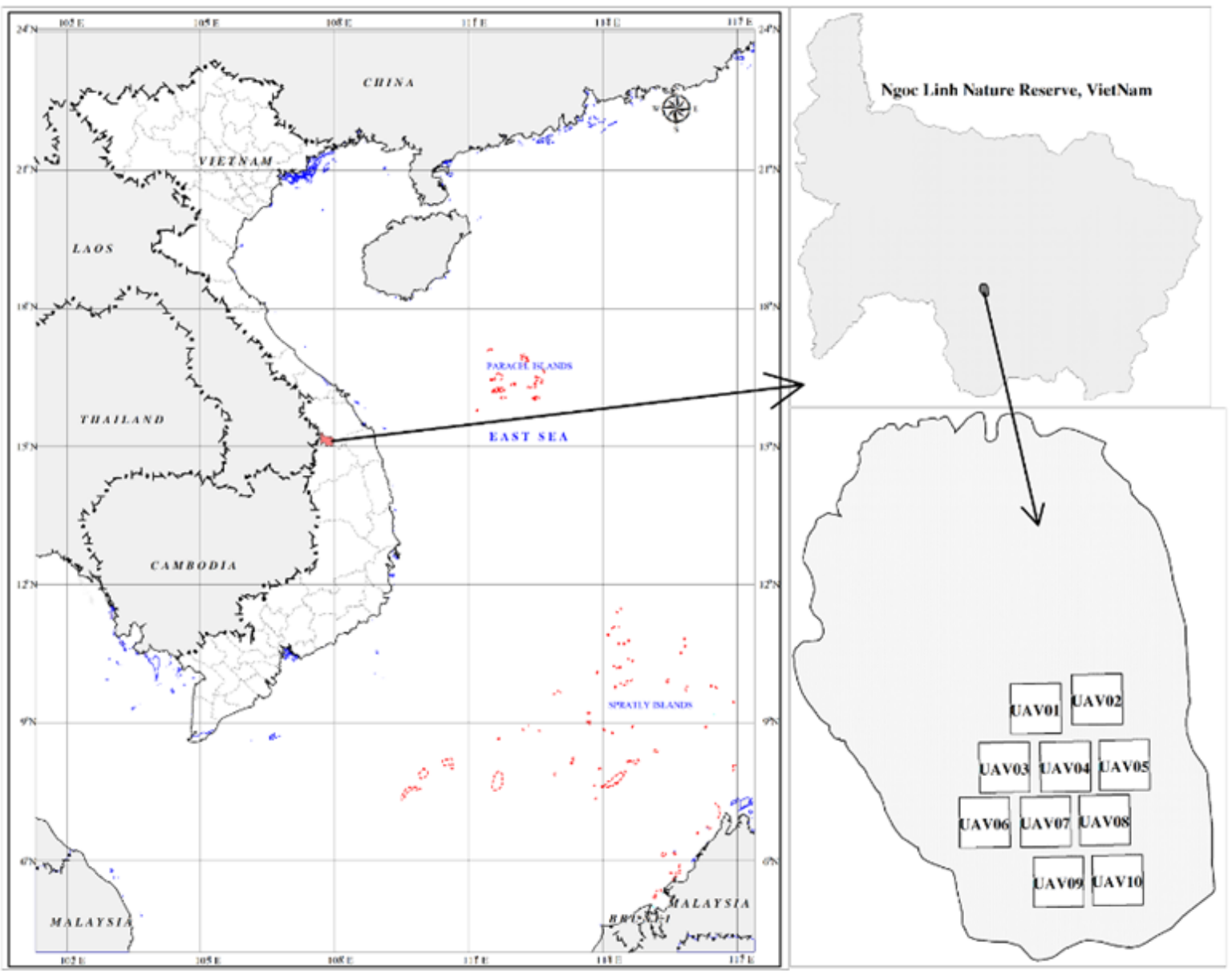

Figure 1. Location of studied sites

Belonging to the tropical monsoon region, the plateau monsoon dependent system is divided into two distinct seasons: dry season and rainy season. The rainy season usually starts from the beginning of the last month of May to the end of November, the dry season from December to the beginning of May of the following year. This is the source of major rivers including Dak Mek River which originates from Ngoc Linh Peak, Dak Po Ko River originates from the peaks of over 2,000 meters high. The terrain is complicatedly differentiated, the terrain slope is very large, popular from 40 to $45^{\circ}$, in many places up to 60 to $65^{\circ}$, stretching from highlands, high mountains to medium mountains and valleys. Accordingly, the soil system is divided quite diversely into 4 groups, 9 types of soil according to the classification system of FAO / UNESCO (Ngo et al., 2020). Feralit red soil and red soil - Ferralsols and Acrisols (Ngo et al., 2020) are common at almost all levels in mountainous areas.

Ngoc Linh nature reserve is the residential area of the people of the Gie Trieng, Ta Gie, Kinh, and Xe Dang ethnic groups, with relatively different production and living customs in the region; It still preserves its own characteristics of the traditional folk culture of their own people. Economic activities are mainly agricultural production, including cultivation and husbandry. Shifting cultivation is a popular form, a source of food and food for the indigenous people. 
Ngoc Linh nature reserve is one of the highest biodiversity conservation areas and national parks in Vietnam. The nature reserve has a rich variety of vegetation types, characterized by the following groups: evergreen broadleaf forests, coniferous forests, mixed broadleaf and coniferous forests, mixed forests (trees and bamboo), bamboo forests and grasslands, shrubs (Thai Van Trung, 1978). The local fauna also has unique characteristics of an upland region, with many rare and valuable mammals, birds, amphibians and insects that are of high conservation values.

Table 1. Main characteristics of 10 survey spots

\begin{tabular}{|c|c|c|c|c|c|}
\hline No. & Code & Main features & No. & Code & Main features \\
\hline 1 & UAV01 & $\begin{array}{l}\text { Altitude UAV: } 1,240 \text { - 1,290m } \\
\text { Typical vegetation: Mixed broad- } \\
\text { leaved, coniferous forest } \\
\text { dominated by species }\end{array}$ & 6 & UAV06 & $\begin{array}{l}\text { Altitude UAV: } 1,165-1,232 \mathrm{~m} \\
\text { Typical vegetation: } \\
\text { Broad leaved forest and } \\
\text { dominative grassland }\end{array}$ \\
\hline 2 & UAV02 & $\begin{array}{l}\text { Altitude UAV: } 1,301-1,330 \mathrm{~m} \\
\text { Typical vegetation: Broad leaved } \\
\text { forest dominates }\end{array}$ & 7 & UAV07 & $\begin{array}{l}\text { Altitude UAV: } 1,245-1,280 \mathrm{~m} \\
\text { Typical vegetation: Dominative } \\
\text { mixed broadleaf and coniferous } \\
\text { forests }\end{array}$ \\
\hline 3 & UAV03 & $\begin{array}{l}\text { Altitude UAV: } 1,217-1,287 \mathrm{~m} \\
\text { Typical vegetation: Broad leaved } \\
\text { forest dominates }\end{array}$ & 8 & UAV08 & $\begin{array}{l}\text { Altitude UAV: } 1,272-1,321 \mathrm{~m} \\
\text { Typical vegetation: Coniferous } \\
\text { forests dominate }\end{array}$ \\
\hline 4 & UAV04 & $\begin{array}{l}\text { Altitude UAV: } 1,295-1,327 \mathrm{~m} \\
\text { Typical vegetation: Coniferous } \\
\text { forests dominate }\end{array}$ & 9 & UAV09 & $\begin{array}{l}\text { Altitude UAV: } 1,192-1,228 \mathrm{~m} \\
\text { Typical vegetation: Mixed } \\
\text { broadleaf and coniferous forests } \\
\text { dominate }\end{array}$ \\
\hline 5 & UAV05 & $\begin{array}{l}\text { Altitude UAV: } 1,340-1,357 \mathrm{~m} \\
\text { Typical vegetation: Coniferous } \\
\text { forests dominate }\end{array}$ & 10 & UAV10 & $\begin{array}{l}\text { Altitude UAV: } 1,241-1,263 \mathrm{~m} \\
\text { Typical vegetation: Broad leaved } \\
\text { forest dominates }\end{array}$ \\
\hline
\end{tabular}

The sample spots cover $100 \times 100 \mathrm{~m}$ ( 1 ha) in size. In the overall mixed forest, each sample spot has a different net structure (Table 1 ).

\subsection{Analysis of UAV images}

Post-processing high resolution RGB band images $(7.85 \mathrm{~cm} /$ pixel in 2019 and $7.74 \mathrm{~cm} /$ pixel in 2020) (Figure 2) were collected at 2 different times in the middle of the rainy season in September 2019. and at the end of the 5/2020 dry season with the UAV Phantom 4 Advanced. This is a quite compact UAV, weighing only $1368 \mathrm{~g}$, with wide-angle camera which can move up and down, it is very easy to carry in conditions of highly divided tropical forests in Vietnam. It is equipped with GPS system to ensure the accuracy in flight programming, it can also withstand winds at $10 \mathrm{~m} / \mathrm{s}$, with $20 \mathrm{MP}$ camera resolution, $35 \mathrm{~mm}$ lens, have the ability of conducting autofocus with Gimbal antishake for camera, which allows the collection of high-resolution, sharp-quality images. In the flight area, the GPS signal is not good enough, leading to the error of the UAV altitude difference between the two flights, causing the pixel size to be different.

The collected image data were processed on Pix4Dmapper software, formatted and processed, and brought back to the WGS 84 coordinate system, UTM zone 48, Northern Hemisphere. The results obtained Orthophotos image (Figure 2 ), on one hand, continue to be processed to give the results of the TGI index according to the formula:

$$
\mathrm{TGI}=-0.5[190 *(\mathrm{R} 670-\mathrm{R} 550)-120 *(\mathrm{R} 670-\mathrm{R} 480)] \text { (Jr et al., 2013). }
$$


DSM, Orthomosaic and Index Details

\begin{tabular}{|c|c|}
\hline DSMand Orthomosaic Resolution & 1 xGSD (7.85 [cm/pixel]) \\
\hline DSMFilters & $\begin{array}{l}\text { Noise Filtering: yes } \\
\text { Surface Smoothing: yes, Type: Sharp }\end{array}$ \\
\hline Raster DSM & $\begin{array}{l}\text { Generated: yes } \\
\text { Method: Inverse Distance Weighting } \\
\text { Merge Tiles: yes }\end{array}$ \\
\hline Orthomosaic & $\begin{array}{l}\text { Generated: yes } \\
\text { Merge Tiles: yes } \\
\text { GeoTIFF Without Transparency. no } \\
\text { Google Maps Tiles and KM: no }\end{array}$ \\
\hline \multicolumn{2}{|c|}{ DSM, Orthomosaic and Index Details } \\
\hline \multicolumn{2}{|c|}{ Processing Options } \\
\hline DSMand Orthomosaic Resolution & 1 xGSD $(7.74[\mathrm{~cm} /$ pixel] $)$ \\
\hline DSMFilters & $\begin{array}{l}\text { Noise Filtering: yes } \\
\text { Surface Smoothing: yes, Type: Sharp }\end{array}$ \\
\hline Raster DSM & $\begin{array}{l}\text { Generated: yes } \\
\text { Method: Inverse Distance Weighting } \\
\text { Merge Tiles: yes }\end{array}$ \\
\hline Orthomosaic & $\begin{array}{l}\text { Generated: yes } \\
\text { Merge Tiles: yes } \\
\text { GeoTiFF Without Transparency. no } \\
\text { Google Maps Tiles and KML: no }\end{array}$ \\
\hline
\end{tabular}

Figure 2. UAV data processing report by Pix4Dmapper in 2 years (2019 and 2020)

Multispectral sensor bands or digital camera bands of red, green and blue may be used instead of narrow bands at 670, 550 and $480 \mathrm{~nm}$, respectively (Doraiswamy, et al. 2013). In order to simplify the formula for calculating TGI and integrate with software we use the formula recognized on the Pix4d website as follows (https://support.pix4d.com/hc/en-us/articles/360000891623-Generate-avegetation-index)

$$
\mathrm{TGI}=(\text { GREEN }-(0.39 * \text { RED })-(0.61 * \text { BLUE }))
$$
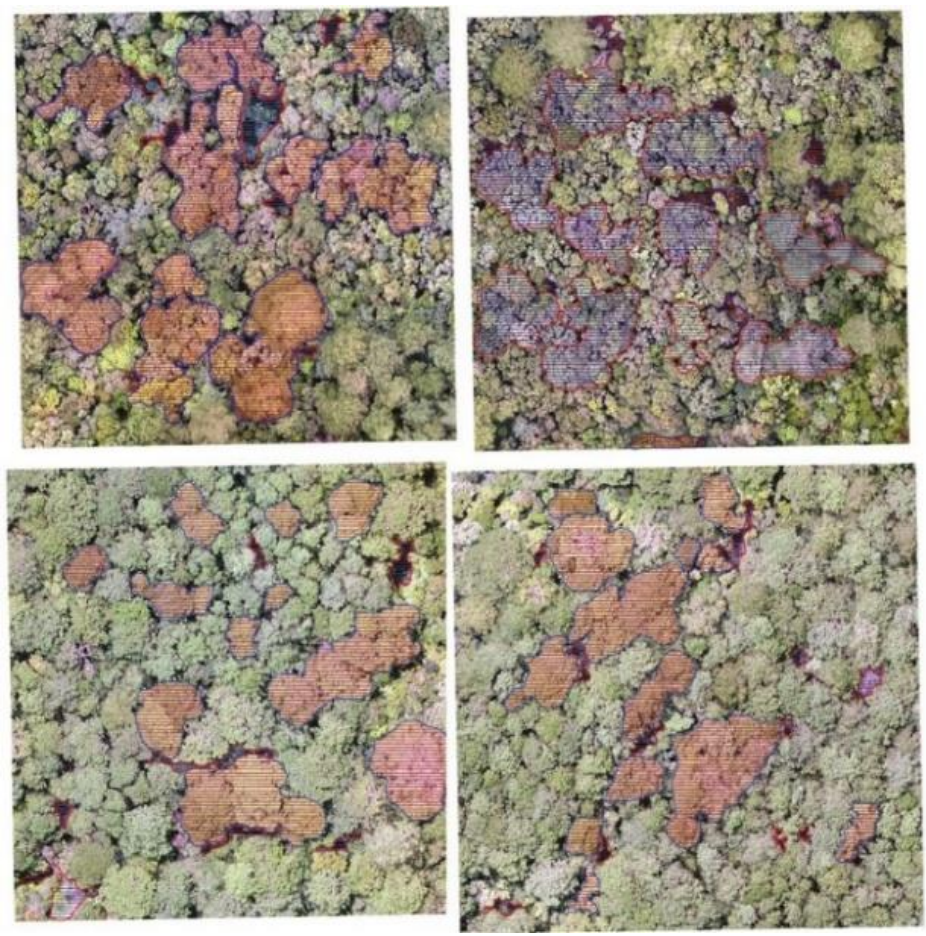

Figure 3. Some selected samples for classification in one ha squares 
After calculation, the data on TGI index were converted to raster in Arcgis 10.5. Selected sites will be classified for inspection using Arcgis 10.5 software (Figure 3 ), with each 1-hectare plot in each season more than 20 classification samples (canopy space and canopy) depending on each differentiation of canopy vegetation of each plot, ensuring an accurate classification (Figure 4). We have used algorithm "Maximum Likelihood Classification" in classifying tree canopy and canopy gaps. This is the method most used by taxonomists in the study of the vegetation cover. Each pixel is calculated the probability of being of some type and it is specifies the assignment of the type name with the greatest probability of belonging to that type.

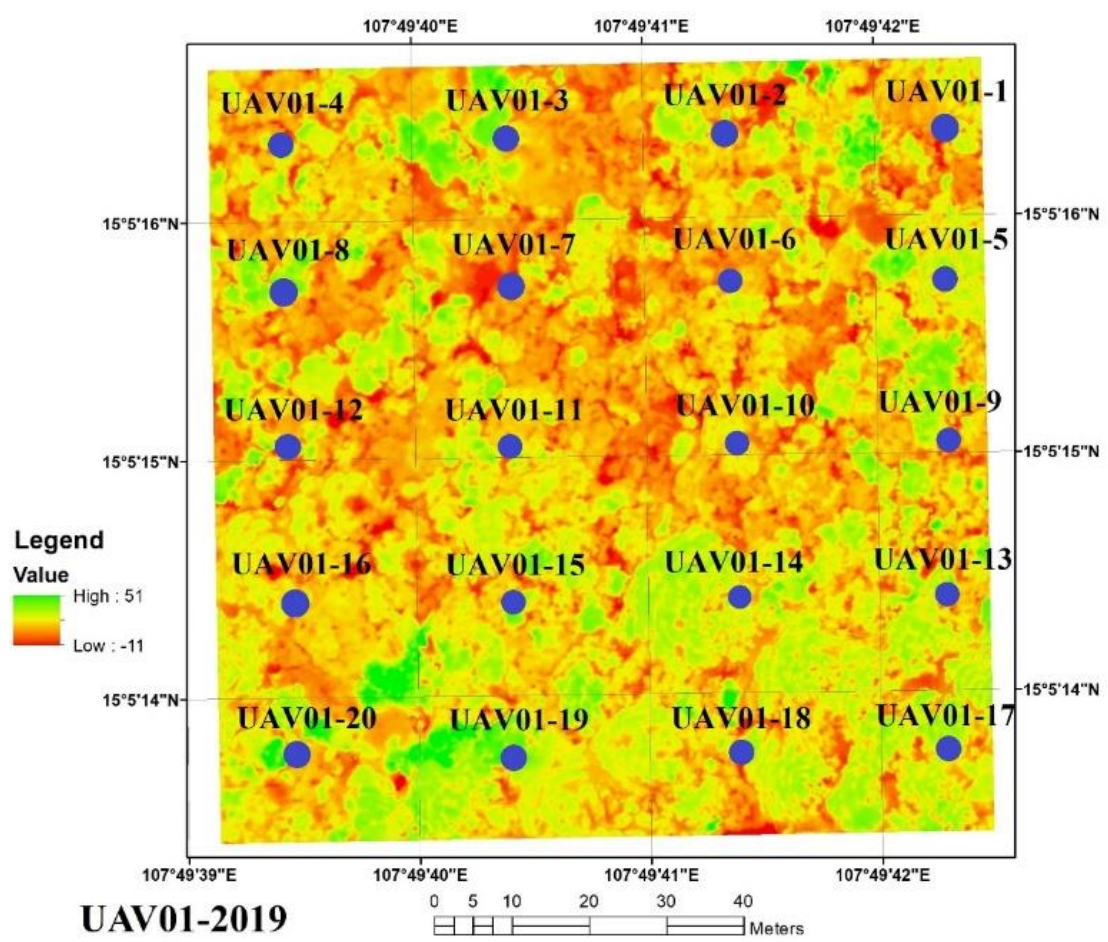

Figure 4. Distribution diagram of points for comparing TGI index in 20 plots in the rainy season in September 2019 and the dry season in May 2020 (taking representative of the UAV01 area)

\section{Results}

The results of verified classification in 10 study areas in the two periods of September 2019 and May 2020 are shown in Figure 4. According to Figure 4 and Table 3 there is a clear variation in canopy gaps in the rainy and dry seasons, especially for the areas where the spread of broadleaf vegetation is dominated. During this period, the coverage ratio of the vegetation cover increased significantly, with around $10 \%$ for the dominant broadleaf vegetation biomes. Meanwhile, for the mixed broadleaf and coniferous forests, the coverage rate increased slightly, in about $3 \%$, some areas kept the same coverage (UAV07).

In particular, for the sample spots with the dominant broadleaf forest communities of UAV02, UAV03 and UAV10, the proportion of canopy area increased by $10 \%$ and $9 \%$, respectively, reaching $83 \%$ of the total sample plot area. Meanwhile, for the mixed broadleaf and coniferous forest spots dominated (UAV01, UAV07, UAV09), the coverage rate increased slightly, in about 3\%, some areas remained the same coverage (UAV07). The rate of foliage area by May 2020 in the above areas will reach $77-79 \%$ of the sample plot area. In the sample plot UAV06, where there is a large proportion of canopy gaps, the coverage rate is even slightly decreased, from $63 \%$ to $58 \%$.

The plots in the slope area (UAV04, UAV09) have more stable variation in coverage than the areas with lower slope (UAV02, UAV05) in the period between the rainy and rainy seasons. This can be clearly seen in the area where conifers are dominant (UAV04), when the percentage of canopy fluctuates between the two seasons is $3 \%$ ( 74 and $77 \%$ ), while in the UAV08 area it is 74 and $82 \%$, respectively. With mixed broadleaf and coniferous areas, the variation in \% of canopy between 
slopes with different slopes is not too great, for UAV07 area it is stable at 77\%, while for UAV09 area, $\%$ of canopy ranges from $72 \%$ up to $76 \%$ in the mid-season period.

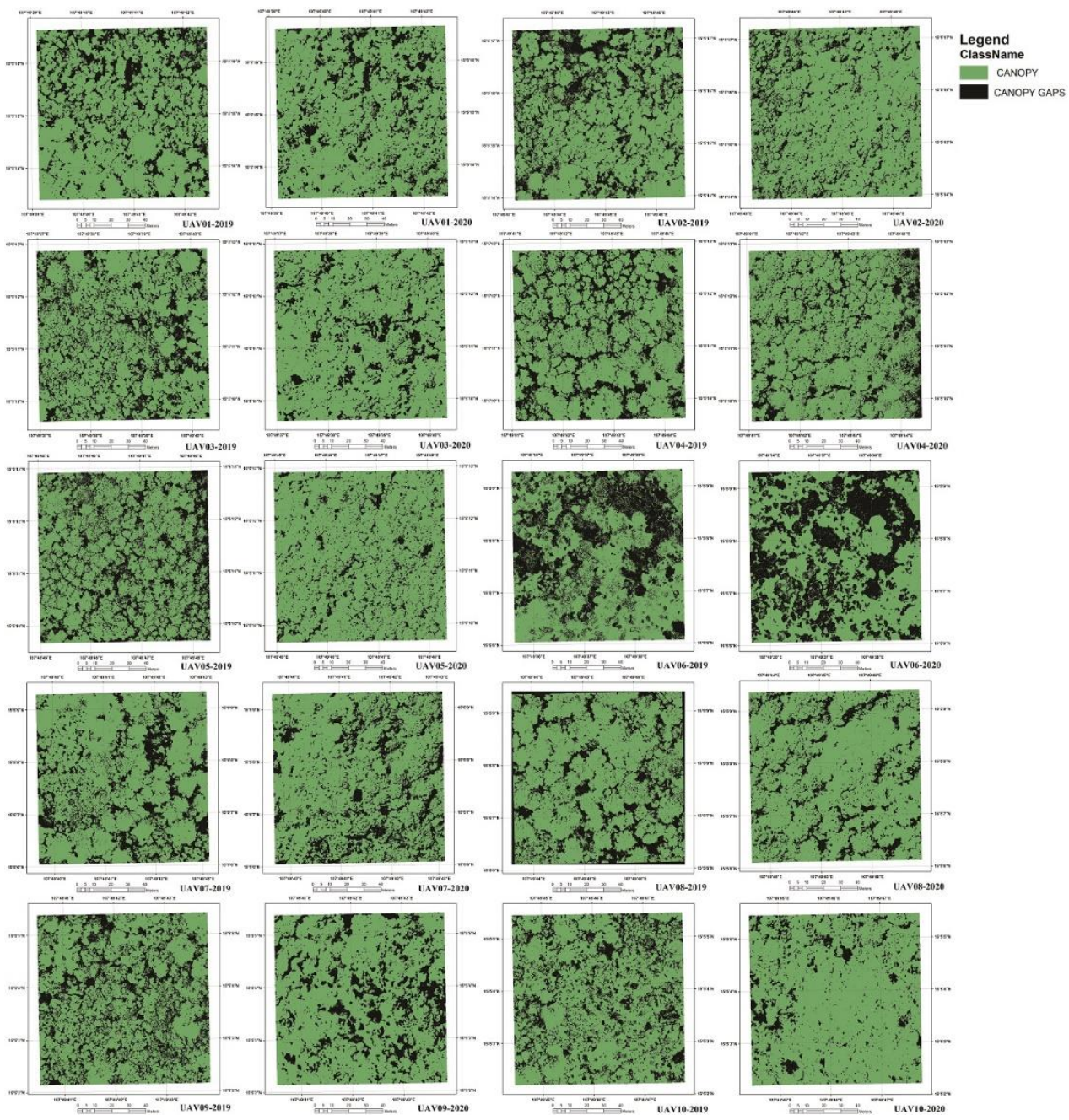

Figure 5. Classification results test 10 areas with an area of $100 \mathrm{~m} \times 100 \mathrm{~m}$ (1ha), of which: (left) time of flight taken in rainy season 9/2019; (right) Images from flights taken in the dry season 5/2020

For the sample spots of coniferous vegetation that dominates, including UAV04, UAV05, UAV08, there is a marked decrease in the area of gaps in forest canopy. Specifically, in the UAV04 sample plot, the proportion of forest canopy gaps decreased from $26 \%$ to $23 \%$ between September 2019 and May 2020. Similar to the UAV05 sample plot, the percentage of forest canopy gaps is also reduced, from 30\% in September 2019 to only 14\% in May 2020. The UAV08 sample plot also reduced the area of the forest canopy gaps (26\% in September 2019 to 18\% in May 2020).

However, it can be seen that there are many gaps in the forest canopy with a small area, scattered and unfocused. These gaps have a huge variation over the rainy and dry season, when most of them are disturbed, disappear or form new gaps of small area during this period. The gaps with large areas have a change in shape, tend to narrow the area during the research period. Typically, in the UAV02 area, the large gaps have almost been altered, almost disappeared. In the remaining areas, in the dry season of May 2020, large gaps are narrowed in relatively large areas, forming smaller canopy gaps, more fragmented compared to the rainy season in September 2019. In the area of UAV06, the forest canopy gaps are distributed concentrated, large area, the area where grasslands are gradually recovering. This is an area with the participation of shrubland communities with a large concentration area. Therefore, the area of canopy gaps in this area accounts for a relatively high proportion (37\% in 2019 and 42\% in 2020) (Table 2). 


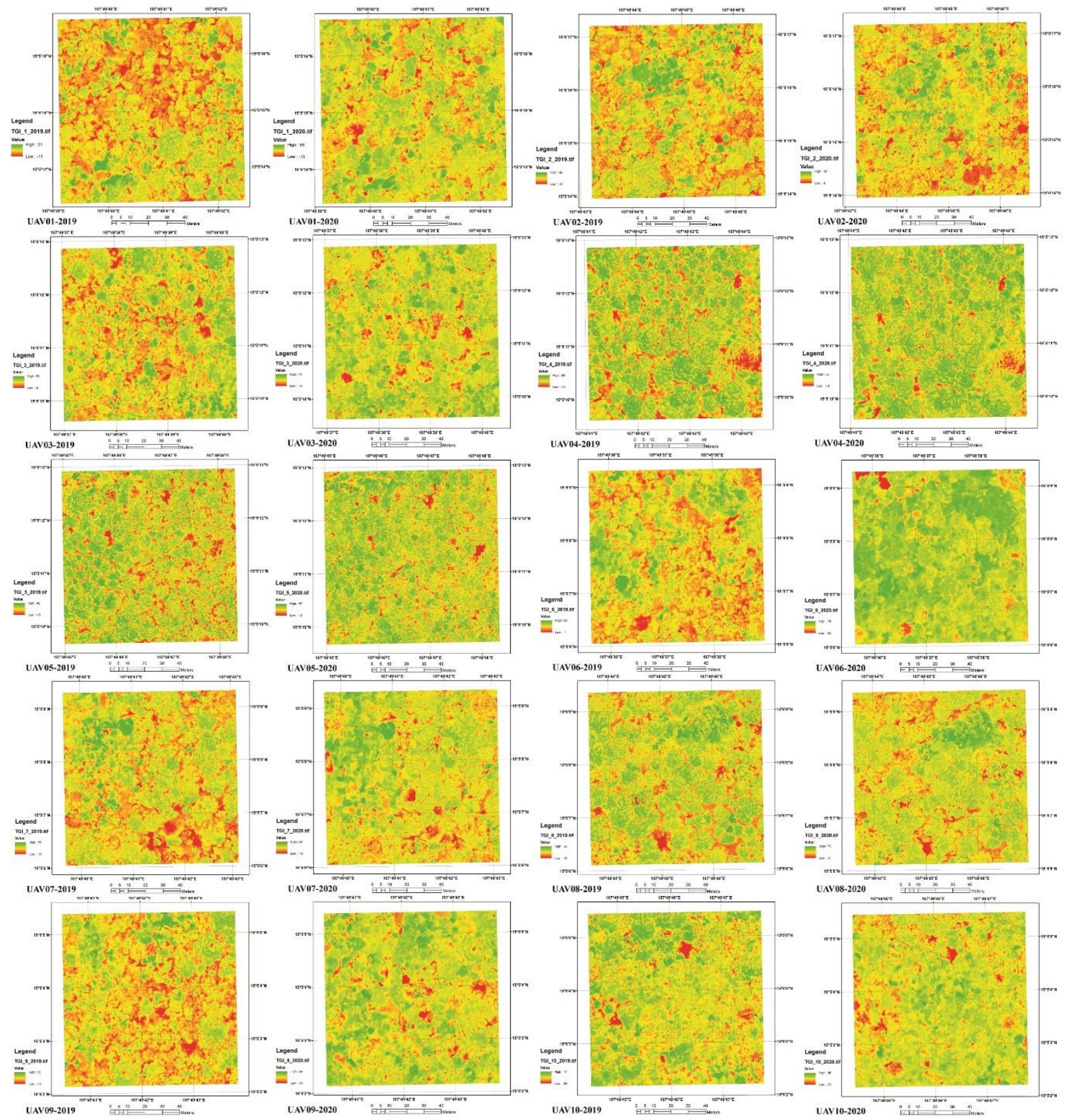

Figure 6. Results of analysis of TGI index of 10 areas with an area of $100 \mathrm{~m} \times 100 \mathrm{~m}$ (1ha), of which: (left) time of flight taken in rainy season 9/2019; (right) Images from flights taken in the dry season $5 / 2020$

Table 2. Statistics of vegetation cover type, coverage ratio and TGI index at UAV shooting points

\begin{tabular}{|l|l|c|c|c|c|}
\hline \multicolumn{1}{|c|}{ Regions } & \multicolumn{1}{|c|}{ Vegetations } & $\begin{array}{c}\% \\
\text { Canopy }\end{array}$ & $\begin{array}{c}\text { \% Canopy } \\
\text { gaps }\end{array}$ & TGI min & TGI max \\
\hline UAV01-2019 & Mixed broadleaf and coniferous & 76 & 24 & -11 & 51 \\
\hline UAV01-2020 & Mixed broadleaf and coniferous & 79 & 21 & -13 & 68 \\
\hline UAV02-2019 & Broadleaf trees dominate & 73 & 27 & -10 & 56 \\
\hline UAV02-2020 & Broadleaf trees dominate & 83 & 17 & -8 & 92 \\
\hline UAV03-2019 & Broadleaf trees dominate & 74 & 26 & -8 & 63 \\
\hline UAV03-2020 & Broadleaf trees dominate & 83 & 17 & -13 & 74 \\
\hline UAV04-2019 & Coniferous forests dominate & 74 & 26 & -16 & 58 \\
\hline UAV04-2020 & Coniferous forests dominate & 77 & 23 & -13 & 58 \\
\hline UAV05-2019 & Coniferous forests dominate & 70 & 30 & -15 & 40 \\
\hline UAV05-2020 & Coniferous forests dominate & 86 & 14 & -13 & 57 \\
\hline UAV06-2019 & Large-leaved forests and & 63 & 37 & -4 & 63 \\
\hline
\end{tabular}




\begin{tabular}{|l|l|c|c|c|c|}
\hline \multicolumn{1}{|c|}{ Regions } & \multicolumn{1}{|c|}{$\begin{array}{c}\text { Vegetations } \\
\text { Canopy }\end{array}$} & $\begin{array}{c}\text { \% Canopy } \\
\text { gaps }\end{array}$ & TGI min & TGI max \\
\hline UAV06-2020 & $\begin{array}{l}\text { grassland dominate } \\
\text { Large-leaved forests and } \\
\text { grassland dominate }\end{array}$ & 58 & 42 & -22 & 74 \\
\hline UAV07-2019 & Mixed broadleaf and coniferous & 77 & 23 & -11 & 55 \\
\hline UAV07-2020 & Mixed broadleaf and coniferous & 77 & 23 & -12 & 64 \\
\hline UAV08-2019 & Coniferous forests dominate & 74 & 26 & -12 & 66 \\
\hline UAV08-2020 & Coniferous forests dominate & 82 & 18 & -8 & 72 \\
\hline UAV09-2019 & Mixed broadleaf and coniferous & 72 & 28 & -13 & 55 \\
\hline UAV09-2020 & Mixed broadleaf and coniferous & 76 & 24 & -10 & 64 \\
\hline UAV10-2019 & Broadleaf trees dominate & 76 & 24 & -24 & 47 \\
\hline UAV10-2020 & Broadleaf trees dominate & 88 & 12 & -13 & 96 \\
\hline
\end{tabular}

Based on the results in Figure 5 and Table 2, in general, the TGI indexes in all regions have shown strong signs of increase. In particular, in the mixed broadleaf and coniferous vegetation, the TGI index increased strongly, typically in areas UAV07 and UAV09. In the UAV06 area, where vegetation is dominated by broadleaf trees and grassland, the growth in TGI is also very significant. Similarly, the dominant broadleaf and coniferous vegetation study areas all experienced noticeable increase in the TGI index during this period. TGI represents the chlorophyll value of leaves, therefore in terms of points with a value less than 8, this is an area of no canopy cover, or in other words, canopy gaps. In areas with high forest canopy cover, the TGI values obtained were high in both study seasons. However, this is not reasonable when in the UAV06 area. The reason is that in the gaps in the forest canopy in this area, there is a large layer of grassland and shrubs, leading to a higher value of TGI in these canopy gaps.
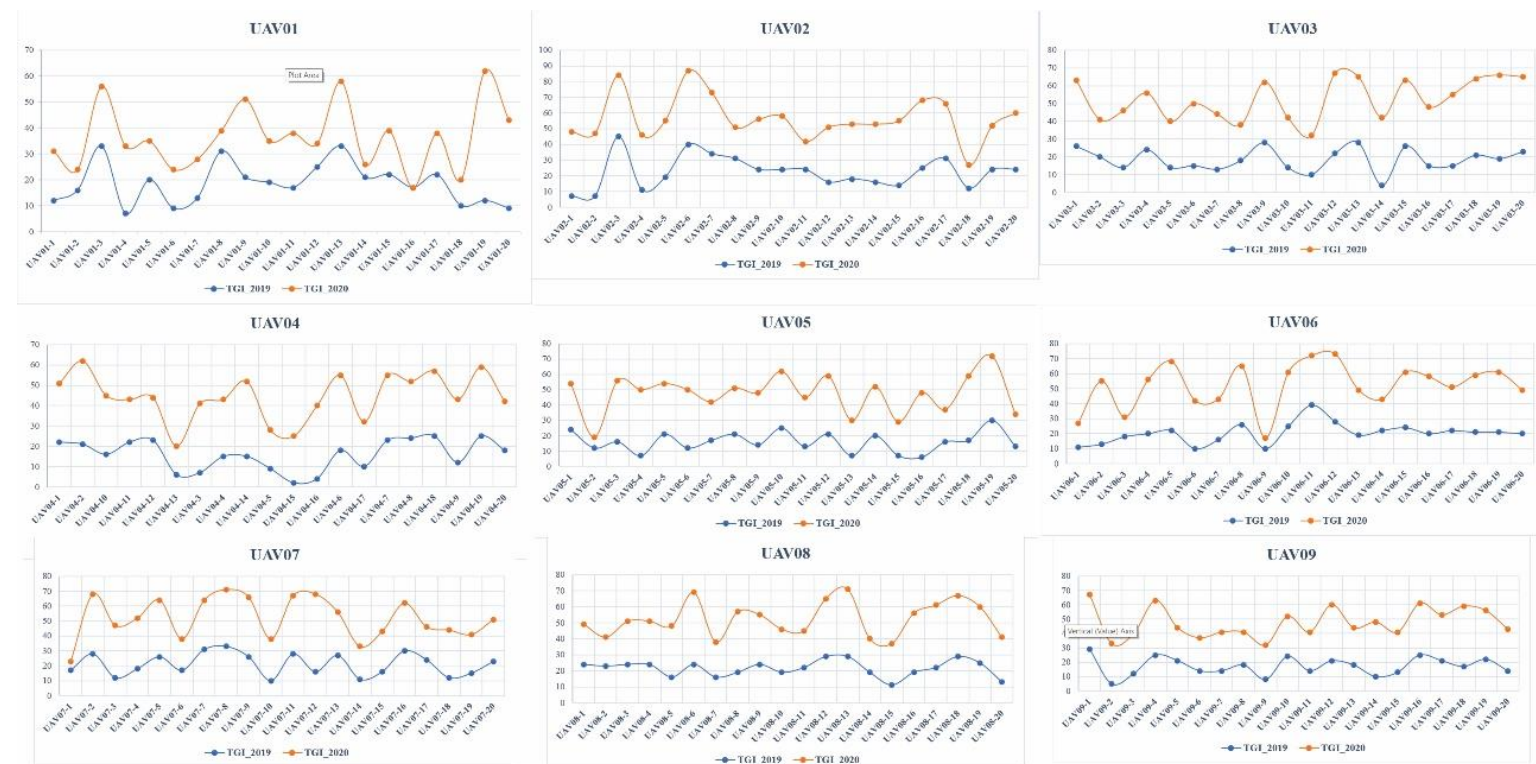

UAV
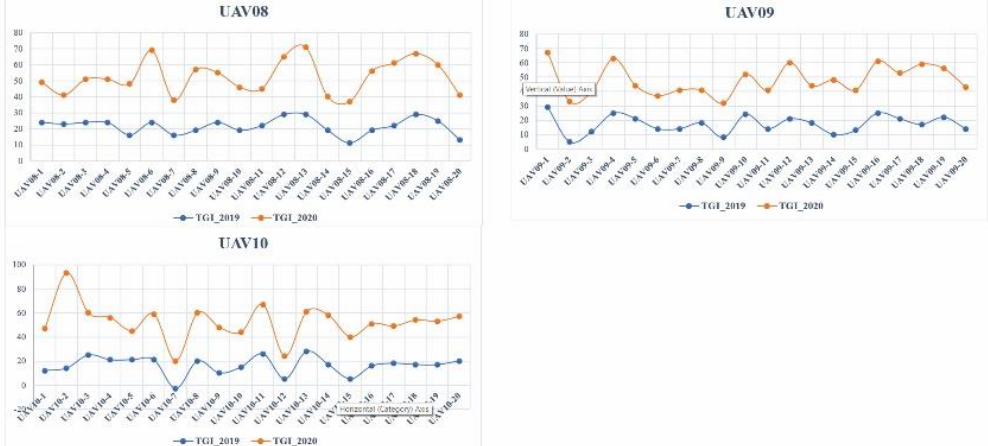

Figure 7. Analysis results of TGI index of 20 points distributed in 10 regions during rainy season in September 2019 and dry season 05/2020 
To compare the TGI index in the rainy season in September 2019 and the dry season in May 2020, we selected 20 sampling points in each region (Figure 5), comparing the TGI index at each time. According to the results shown in Figure 7, it is clearly demonstrated that the plant growth through the TGI value increased during the study period. In terms odd most sample points, the TGI index had a strong growth, the data of some points also increased dramatically such as UAV03-14, UAV 05-4, UAV09-2, UAV10-2, ... The canopy gaps in the rainy season are covered by regenerated trees. The sample points of broadleaf canopy also had a great change in the TGI index, when it increased in the range of 10-20 index units. Sample points of coniferous canopy showed a slight increase in TGI index.

\section{Discussion}

Remote sensing application in assessing seasonal variability or plant indicators in forests is a modern method and commonly used (Bullock et al., 2018; Caron et al., 2009; Getzin et al., 2014; Hopkinson, 2007; Jr et al., 2013; Rautiainen et al., 2012). In this study, UAV has been used as an equipment for the researchers to study the particular seasonal changes in tropical forests altitude above $1000 \mathrm{~m}$ in Ngoc Linh nature reserve, Vietnam through analyzing the percentage of canopy gap and plant TGI. The decrease in the area of forest canopy gaps and the strong growth of the TGI in the period between two seasons are important criteria for evaluating the seasonal variation and seasonal dynamics of the tropical forests zone. The results show a sharp decrease in the area of canopy gaps in coniferous broadleaf mixed forest, which are dominant broadleaf forest, one of them is in Ngoc Linh forest. The TGI analysis results show their strong increase, especially in the areas where the gaps have been altered, covered with leaves during the period between the wet and dry seasons. At the sample sites studied, most of the TGI index showed signs of increasing during this period.

The study results showed that the mixed broadleaf and coniferous vegetation have strong fluctuations in the rainy and dry seasons. This is consistent with the study of Getzin 2014 confirmed in his research on the application of remote sensing in determining forest canopy gaps in Germany. The application of remote sensing and GIS in determining forest canopy gaps gives more detailed results, in order to assess the seasonal variation of forest vegetation more clearly. Getzin 2014 also showed gaps larger than $1 \mathrm{~m}^{2}$ when applying GIS in determining canopy gaps. This is considered a modern method, giving more accurate results than the study of Caron 2009 (Caron et al., 2009) when using only measuring devices along a linear section about $400 \mathrm{~m}$ long. For pure coniferous communities such as UAV04, UAV05 and UAV08, variation in vegetative indicators is smaller than that of broadleaf or mixed broadleaf and coniferous communities. This property is also consistent with research results of Kuznetsov A.N. and colleagues in tropical forests with elevation over 1,000 $\mathrm{m}$, including Ngoc Linh Nature Reserve. Accordingly, conifers such as Pinus kesiya only partially defoliate and distribute all year round, broadleaf species of the family Fagaceae, Euphorbiaceae, Lauraceae, Magnoliacea, Elaeocarpaceae (is the main component of the studied vegetation cover). The falling time happens mostly in the cold season at the end of the year, from November to February of the following year, creating a clear seasonal differentiation and the falling time lasts for 1.5 to 2 months (Nikolaevich, 2015).

The vegetation cover at Ngoc Linh, especially in the area which is dominated by broadleaf trees, grows strongly during the rainy season. During the UAV data collection in September 2019, many tree species were in the flowering period, creating the bright top surface of the canopy, so the TGI indicators at this time were relatively low. Meanwhile, in May 2020, at the end of the dry season, the high temperature coniferous broadleaf community develops relatively well, the leaf cover level is high, the canopy coverage index and the chlorophyll content in leaves are high, so the TGI index is also quite large compared to the rainy season. It is noted at this time that the flowering density of broadleaf trees is quite small, instead of the covered area by leaves. Coniferous trees (mainly Pinus kesiya) grow well, with a higher coverage than in the rainy season. The early rainfalls in the season of May together with the increased heat caused the growth of plants to be greater during this period (Nikolaevich, 2015). Strong leaf growth at the end of the dry season facilitates maximizing the length of the growing season by producing young leaves, which effectively photosynthesize 
before the onset of the rainy season, consistent with the study of Elliott (Elliott et al., 2006; Elliott et al., 2002). The physiological complexity of each species and the natural geographic conditions in the area lead to a significant variation of leaves between periods of the year (Williams et al., 2008). That is shown in this study through analysis of TGI index at 2 points of time UAV data was collected. The study has shown the seasonal variation of different types of flora at altitudes above $1,000 \mathrm{~m}$ through the canopy gap index and TGI, however, due to equipment limitations, has not modeling canopy structure at two times in rainy season and dry season. This has been shown by Zahawi (2015) with a UAV application with a LiDAR sensor attached (Zahawi et al., 2015).

It can be seen that the variation of the canopy gaps is closely related to the vegetation index in the rainy and dry seasons. Determination of variation in canopy gaps and their relationship to vegetative indicators based on UAV data is an important result in the assessment of seasonal variation, particularly in tropical forest areas, where there is a clear split between wet and dry seasons. Regenerating vegetation, which grows strongly in the late dry season and early rainy season, leads to a decrease in the area of forest canopy gaps and a sharp increase in the vegetative TGI index. In the middle of the rainy season, when the vegetation covers are broadleaf in the reproductive period, flower density is high, the area of forest canopy gaps is large, scattered, and the plant TGI index is low.

The application of UAVs in the study of seasonal variation in tropical forests for small-scaled areas is considered quite appropriate. Using UAV saves time, costs, takes initiative in data acquisition time and are able to reach areas that are hard to access by humans, resulting in high image quality. However, the limitations of the camera mounted on the UAV equipment during the study did not allow us to analyze other characteristic vegetative indices. Sensors with near infrared wavelength (NIR) are important in analyzing the seasonal variation of vegetation. In addition, the verifiable classification of the forest canopy gaps also results in some bias in the results. The deviation in GPS positioning during the flight of the UAV leads to the difference in pixel size. It is necessary to have an RTK locator attached to the UAV to minimize GPS positioning errors during flight capture. In the next studies, we will continue to improve the sensors mounted on the UAV to be able to receive image data with a broader spectrum, facilitating the evaluation of plant indexes. In addition, we will continue to study the relationship between canopy gaps for other vegetation indices (VARI, NDVI) to be able to identify more accurate canopy gaps.

\section{Conclusions}

UAVs are a very suitable tool for assessing canopy gaps as well as vegetation indicators in small, inaccessible forest areas. Based on the analysis of UAV images, we have shown the variation in forest canopy gaps and vegetation indicators during the wet and dry seasons. Evaluating the relationship between these two indicators is an important criterion for determining the dynamics of seasonal variation of the vegetation cover. For vegetation with large presence of broadleaf species, seasonal variation occurs relatively clearly, reflected through leaf regeneration in the open areas from the rainy season to the dry season.

The variation in forest canopy gaps and vegetative indicators are closely related to the high belt differentiation, the seasonal and the dry season climatic characteristics. Analysis of seasonal dynamics of the vegetation cover not only assesses the seasonal changes in tropical flora communities, but also assesses the impact on the habitat of organisms under the forest canopy such as birds, animals, land animals. They are species directly related to the seasonal variation of the vegetation cover. Analyzing the correlation between seasonal variation and the behavior of forest organisms is the scientific basis for resource management and conservation, especially for tropical forest areas where diversity is found. high biology.

With the development of sensors attached on UAV in the near future, we hope to evaluate in more detail the seasonal dynamics of the vegetation through the vegetation indicators. Increasing the image resolution on the wave bands of the camera attached on the UAV also provide a very good condition to increase the accuracy of the forest canopy gap maps and vegetation index maps in the study areas. 
Author Contributions: Nguyen Dang Hoi conceived, designed the experiments and wrote the paper. Ngo Trung Dung performed the experiments and analyzed the data.

Conflicts of Interest: The authors declare no conflict of interest.

Acknowledgments: We sincerely express our sincerity to Vietnam - Russia Tropical Center, Ministry of Defense and the topic "Study on structural features of Ngoc Linh Nature Reserve landscapes, in Kon Tum province on the basis of applying remote sensing method, GIS. and the unmanned aerial vehicle (UAV)" conducted by the Vietnam - Russia Tropical Center in terms of their support both by researching funding, equipment and machines for the authors to complete this article. We would also like to thank the Ngoc Linh Ecology Garden Management Board, Kon Tum Province, for their supporting, providing data and facilitating us during the field survey in September 2019 and May 2020.

\section{References}

Anderson, K., \& Gaston, K. (2013). Lightweight unmanned aerial vehicles will revolutionize spatial ecology. Frontiers in Ecology and the Environment, 11, 138-146. https://doi.org/10.1890/120150

Banu, T., Borlea, G., \& Banu, C. (2016). The Use of Drones in Forestry. Journal of Environmental Science and Engineering B, 5. http://dx.doi.org/10.17265/2162-5263/2016.11.007

Betts, H., Brown, L., \& Stewart, G. (2005). Forest canopy gap detection and characterisation by the use of high-resolution Digital Elevation Models. New Zealand Journal of Ecology, 29.

Bongjoh, C., \& Mama, N. (2020). Early regeneration of commercial timber species in a logged-over forest of southern Cameroon. Tropenbos International.

Brokaw, N., \& Busing, R. (2000). Niche versus Chance and Tree Diversity in Forest Gaps. Trends in Ecology \& Evolution, 15, 183-188. https://doi.org/10.1016/s0169-5347(00)01822-x

Brovkina, O., Cienciala, E., Surovy, P., \& Janata, P. (2018). Unmanned aerial vehicles (UAV) for assessment of qualitative classification of Norway spruce in temperate forest stands. Geospatial Information Science, 21, 1-9. http://dx.doi.org/10.1080/10095020.2017.1416994

Bullock, E., Woodcock, C., \& Olofsson, P. (2018). Monitoring tropical forest degradation using spectral unmixing and Landsat time series analysis. Remote Sensing of Environment, 238. http://dx.doi.org/10.1016/j.rse.2018.11.011

Caron, M.-N., Kneeshaw, D., Grandpré, L., Kauhanen, H., \& Kuuluvainen, T. (2009). Canopy Gap Characteristics and Disturbance Dynamics in Old-Growth Picea abies Stands in Northern Fennoscandia: Is the Forest in Quasi-Equilibrium? Annales Botanici Fennici, 46, 251-262. https://doi.org/10.5735/085.046.0402

Chung, C.-H., \& Huang, C.-y. (2020). Hindcasting tree heights in tropical forests using time-series unmanned aerial vehicle imagery. Agricultural and Forest Meteorology, 290, 108029. http://dx.doi.org/10.1016/j.agrformet.2020.108029

Collins, B., Dunne, K., \& Pickett, S. T. A. (1985). Responses of Forest Herbs to Canopy Gaps. The Ecology of Natural Disturbance and Patch Dynamics. https://doi.org/10.1016/B978-0-08050495-7.50017-X

Csillik, O., Kumar, P., \& Asner, G. (2020). Challenges in Estimating Tropical Forest Canopy Height from Planet Dove Imagery. Remote Sensing, 12, 1160. https://doi.org/10.3390/rs12071160

Denslow, J. S. (1987). Tropical Rainforest Gaps and Tree Species Diversity. Annual Review of Ecology and Systematics, 18(1), 431-451. https://doi.org/10.1146/annurev.es.18.110187.002243

Elhag, M. (2015). Tropical Forests Mapping of Bioko Island Using Remote Sensing Techniques. Journal of King Abdulaziz University - Meteorology, Environment and Arid Land Agriculture Sciences, 26, 95-109. http://dx.doi.org/10.4197/Met.26-2.10

Elliott, S., Baker, P., \& Borchert, R. (2006). Leaf flushing during the dry season: The paradox of Asian monsoon forests. Global Ecology and Biogeography, 15, 248-257. https://doi.org/10.1111/j.1466-8238.2006.00213.x

Elliott, S., Caldas, L., Nicolossi, G., Coradin, V., \& Borchert, R. (2002). Increasing day-length induces flushing of tropical dry forest trees in the absence of rain. Trees, 16, 445-456. https://doi.org/10.1007/s00468-002-0185-3 
Eysenrode, D., Kockelbergh, F., Bogaert, J., Impens, I., \& Hecke, P. (2002). Canopy gap edge determination and the importance of gap edges for plant diversity. Web Ecology, 3, 1-5. http://dx.doi.org/10.5194/we-3-1-2002

Fernandez-Diaz, J., Carter, W., Shrestha, R., \& Glennie, C. (2020). LiDAR REmote Sensing. In J. N. Pelton, S. Madry, S. Camacho-Lara (eds.), Handbook of Satellite Applications (pp. 1-52). Springer International Publishing.

Forman, R., \& Collinge, S. (1997). Nature conserved in changing landscapes with and without spatial planning. Landscape and Urban Planning, 37, 129-135. http://dx.doi.org/10.1016/S01692046(96)00378-7

Gagnon, J., Jokela, E., Moser, W., \& Huber, D. (2003). Characteristics of gaps and natural regeneration in mature longleaf pine flatwoods ecosystems. Forest Ecology and Management, 187, 373-380. http://dx.doi.org/10.1016/j.foreco.2003.07.002

Getzin, S., Nuske, R., \& Wiegand, K. (2014). Using Unmanned Aerial Vehicles (UAV) to Quantify Spatial Gap Patterns in Forests. Remote Sensing, 6, 6988-7004. http://dx.doi.org/10.3390/rs6086988

Gray, A., Spies, T., \& Easter, M. (2002). Microclimatic and soil moisture responses to gap formation in coastal Douglas-fir forests. Canadian Journal of Forest Research-revue Canadienne De Recherche Forestiere, 32, 332-343. https://doi.org/10.1139/x01-200

Hart, J., \& Grissino-Mayer, H. (2009). Gap-scale disturbance processes in secondary hardwood stands on the Cumberland Plateau, Tennessee, USA. Forest Ecology: Recent Advances in Plant Ecology, 131-146. http://dx.doi.org/10.1007/s11258-008-9488-9

Hopkinson, C., \& Chasmer, L. E. (2007). Modelling Canopy Gap Fraction from Lidar Intensity. In Proceedings of ISPRS Workshop on Laser Scanning 2007 and SilviLaser 2007, Espoo, Finland, September 12-14, 2007; In The International Archives of the Photogrammetry and Remote Sensing and Spatial Information Sciences. ISPRS: Vienna, Austria, Vol. XXXVI, Part 3/W52. pp. 190-194.

Hubbell, S.P. and Foster, R.B. (1986) Canopy Gaps and the Dynamics of a Neotropical Forest. In Crawley, M.J., (Ed.) Plant Ecology. pp. 77-96. Blackwell.

Jr, E. H., Doraiswamy, P., McMurtrey, J., Daughtry, C., Perry, E., \& Akhmedov, B. (2013). A visible band index for remote sensing leaf Chlorophyll content at the Canopy Scale. International Journal of Applied Earth Observation and Geoinformation, 21, 103-112. https://doi.org/10.1016/j.jag.2012.07.020

Kimmins, J. (2004). Emulating Natural Forest Disturbance: What Does This Mean? In Perera A., Buse L., \& Weber M. (Eds.), Emulating Natural Forest Landscape Disturbances: Concepts and Applications (pp. 8-28). Columbia University Press.

Kirchner, N., Hutter, K., Jakobsson, M., \& Gyllencreutz, R. (2011). Capabilities and limitations of numerical ice sheet models: a discussion for Earth-scientists and modelers. Quaternary Science Reviews, 30(25-26), 3691-3704. http://dx.doi.org/10.1016/j.quascirev.2011.09.012

van der Maarel E. (1988) Vegetation dynamics: patterns in time and space. In: Miles J., Schmidt W., van der Maarel E. (eds) Temporal and Spatial Patterns of Vegetation Dynamics. Advances in vegetation science, vol 9. Springer, Dordrecht. https://doi.org/10.1007/978-94-009-2275-4_1

Marchi, A., \& Paletto, A. (2010). Relationship between forest canopy and natural regeneration in the subalpine spruce-larch forest (north-east Italy). Folia Forestalia Polonica, Series A, 52. http://dx.doi.org/10.5281/zenodo.30770

Muscolo, A., Bagnato, S., Sidari, M., \& Mercurio, R. (2014). A review of the roles of forest canopy gaps. Journal of Forestry Research, 25, 725-736. http://dx.doi.org/10.1007/s11676-014-05217

Muscolo, A., Sidari, M., \& Mercurio, R. (2007). Influence of gap size on organic matter decomposition, microbial biomass and nutrient cycle in Calabrian pine (Pinus laricio, Poiret) stands. Forest Ecology and Management, 242, 412-418. http://dx.doi.org/10.1016/j.foreco.2007.01.058 
Ngo, D., Nguyen, H., Dang, C., \& Kolesnikov, S. (2020). UAV application for assessing rainforest structure in Ngoc Linh nature reserve, Vietnam. E3S Web of Conferences, 203, 03006. http://dx.doi.org/10.1051/e3sconf/202020303006

Nieschulze, J., Zimmermann, R., A, B., \& Schulze, E. D. (2012). An assessment of forest canopy structure by LiDAR: Derivation and stability of canopy structure parameters across forest management types. Forstarchiv, 83, 195-209. http://dx.doi.org/10.4432/0300-4112-83-195

Nikolaevich, K. A. (2015). Structure and dynamics of monsoon tropical forests of Vietnam. Moscow.

Rautiainen, M., Heiskanen, J., \& Korhonen, L. (2012). Seasonal changes in canopy leaf area index and MODIS vegetation products for a boreal forest site in central Finland. Boreal Environment Research, 17.

Richards, P. W., Walsh, R. P. D., Baillie, I., \& Greg-Smith, P. (1996). The tropical rain forest: An ecological study, Second edition. Cambridge University Press.

Trung, T. V. (1978). Forest vegetation in Vietnam. Science and Technology Publishing House.

Watt, A. (1947). Pattern and Process in the Plant Community. Journal of Ecology, 35, 1-22. https://doi.org/10.2307/2256497

Whitmore, T. (1989). Canopy Gaps and the Two Major Groups of Forest Trees. Ecology, 70(3), 536538. https://doi.org/10.2307/1940195

Williams, L., Bunyavejchewin, S., \& Baker, P. (2008). Deciduousness in a seasonal tropical forest in western Thailand: Interannual and intraspecific variation in timing, duration and environmental cues. Oecologia, 155, 571-582. https://doi.org/10.1007/s00442-007-0938-1

Wulder, M., Bater, C., Coops, N., Hilker, T., \& White, J. (2008). The role of LiDAR in sustainable forest management. The Forestry Chronicle, 84, 807-826. http://dx.doi.org/10.5558/tfc84807-6

Zahawi, R., Dandois, J., Holl, K., Nadwodny, D., Reid, J., \& Ellis, E. (2015). Using lightweight unmanned aerial vehicles to monitor tropical forest recovery. Biological Conservation, 186, 287-295. http://dx.doi.org/10.1016/j.biocon.2015.03.031 